\title{
DEM-CFD Model Considering Softening Behavior of Ore Particles in Cohesive Zone and Gas Flow Analysis at Low Coke Rate in Blast Furnace
}

\author{
Hiroyuki KUROSAWA, Shouhei MATSUHASHI, Shungo NATSUI, Tatsuya KON, Shigeru UEDA, Ryo INOUE \\ and Tatsuro ARIYAMA
}

Institute of Multidisciplinary Research for Advanced Materials, Tohoku University, Katahira 2-1-1, Aoba-ku, Sendai, 980-8577 Japan. E-mail: b0td5004@s.tohoku.ac.jp

(Received on October 24, 2011; accepted on January 4, 2012)

\begin{abstract}
Since the cohesive zone has a great influence on the gas flow in the blast furnace, modeling of the cohesive zone is considered to be an important subject. In the cohesive zone, the softening and melting behavior of ore particles is affected by the load from the upper layer and the temperature distribution, and the pressure drop of the ore layer increases remarkably due to shrinkage of the ore particles. In this study, a model of the cohesive zone considering physical properties such as Young's modulus was developed on the basis of the discrete element method, which can track the individual motions of the numerous particles in a packed bed. To determine the appropriate Young's modulus of ore particles for the cohesive zone, element model calculations for a softening test under load were carried out, with particular attention to change in the void fraction. The optimized value of Young's modulus value was then introduced in the discrete element method and computational fluid dynamics (DEM-CFD) model. The changes of gas flow in the vicinity of the cohesive zone were visually expressed by this model. These results were similar to those of cold model experiments and the burden structure observed in the dissected blast furnace. The influence of the coke rate on the gas flow was also analyzed using the above model. The change in the gas flow under a low coke rate condition could be well recognized.
\end{abstract}

KEY WORDS: ironmaking; blast furnace; mathematical modeling; cohesive zone; discrete element method; computational fluid dynamics.

\section{Introduction}

Understanding the in-furnace state of the blast furnace is important for blast furnace operation. While this goes without saying, few methods of direct measuring in-furnace conditions are available, and information on conditions in the furnace is limited to local data. Accordingly, estimation and analysis of the total furnace condition by numerical simulation models are of great significance. Precise blast furnace simulation models have been actively researched. ${ }^{1,2)}$ Particularly in recent years, there has been a strong orientation toward low reducing agent rate operation, and blast furnaces with large inner volume exceeding $5000 \mathrm{~m}^{3}$ continue to be the main stream. These trends have heightening the need for development of more accurate models. ${ }^{3)}$

In general, blast furnace simulation models have adopted methods in which the behavior in the furnace is expressed by basic equations using the differential balance of the motions of solids, gases, and liquids, based on continuum modeling. However, the packed bed in a blast furnace comprises individual particles of ore, coke, etc., and the gas flow is controlled by that packed structure and particle motion. In particular, it is extremely important to reproduce the basic layered structure of the blast furnace burden, which is formed at the furnace top and descends under gravitational force. Because continuum models generally treat the motion of solids by approximation as a quasi-fluid, ${ }^{2)}$ such models are limited to quasi-expression of descending behavior, formation of the deadman, etc. Since these phenomena are influenced by the characteristics of the particles comprising the burden, application of the discrete element model (DEM) method, which is based on dynamic motion in individual particle units, has attracted attention. ${ }^{4,5)}$ Research and development on models linking DEM and computational fluid dynamics (CFD) models has been carried out, and a 3dimensional model which expresses the furnace interior as a layered structure has also been proposed. ${ }^{6}$ )

In the blast furnace, a cohesive zone is formed by softening and melting of ore. Because the gas flow permeability in the cohesive zone differs remarkably from that in the lumpy zone, the formation of the cohesive zone has a large influence on gas flow. This means accurate expression of the characteristics of the cohesive zone is extremely important for constructing a precise blast furnace model. However, in modeling the cohesive zone, quantitative expression of the softening and melting phenomena of the ore layer is difficult. In the conventional continuum models, the void fraction of the cohesive zone is given as a specified value for 
the region corresponding to the cohesive zone. ${ }^{7)}$ However, since softening and shrinkage of the ore in the cohesive zone are also affected by various furnace conditions, such as the load of the burden from the upper layer, etc., modeling which reflects these conditions is desirable. Therefore, in this research, a model which is capable of describing the softening and shrinkage characteristics of ore particles by DEM, reflecting the dynamic conditions in the furnace, was studied with the aim of expressing the softening and shrinkage phenomena of ore in the cohesive zone by a DEM-CFD model of the blast furnace.

In DEM, Young's modulus is used to express the hardness of particles. In general, Young's modulus is frequently set in a uniform manner in DEM. However, in the present model, the authors attempted to set an appropriate Young's modulus for expressing the cohesive zone by comparing the change in the void fraction of the ore layer under load, which simulates the cohesive zone, and the change in pressure drop obtained by a softening test under load. The value determined in this manner was then applied to the blast furnace DEM-CFD model. The reproducibility of changes in the void fraction and gas flow in the cohesive zone by this model was confirmed, and an analysis of the gas flow in the vicinity of the cohesive zone was performed. In addition, taking advantage of features of this model, namely, the fact that the model considers the cohesive zone, changes in the gas flow were analyzed by performing calculations for various coke rates in order to study the effect of low coke rate operation on gas flow in blast furnace.

\section{Model of Softening under Load by DEM}

\subsection{Concept of Softening-shrinkage Model by DEM}

Figure 1 shows the concept of Voigt model in DEM and

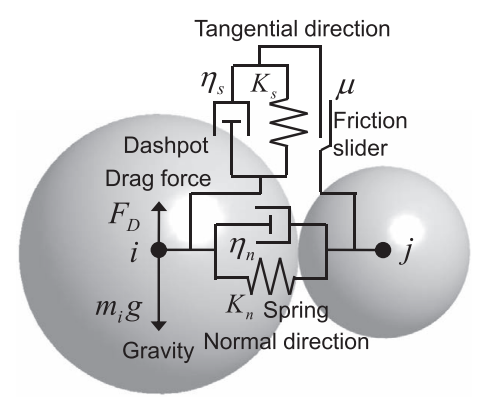

Voigt model

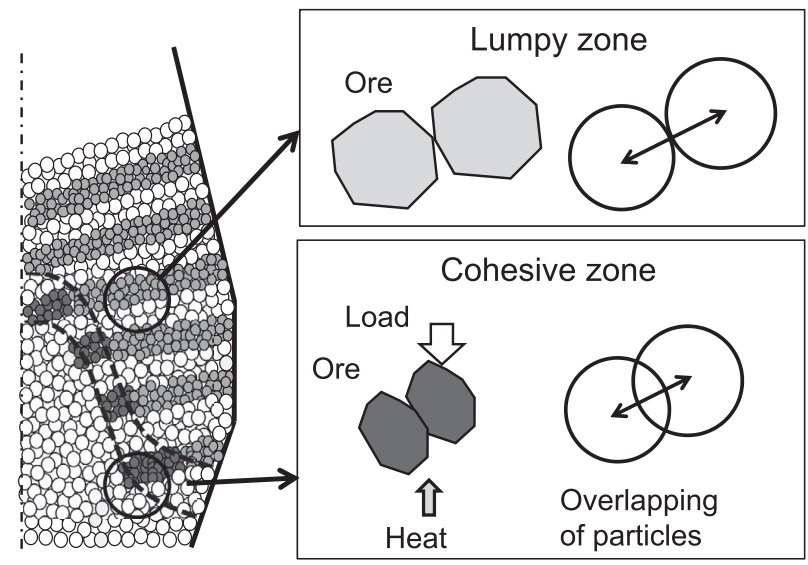

Fig. 1. Concept of Voigt model and softening behavior of ore particles represented in DEM. interparticle distance in the blast furnace lumpy zone and cohesive zone by DEM modeling. In the lumpy zone, point contact occurs between coke and ore layer particles, but this does not reach particle deformation. Therefore, these materials exist as particles which retain their original shapes at the time of charging. In this lumpy zone, a Young's modulus of $1.00 \mathrm{GPa}$ was set for both coke and sinter, referring to previous research. ${ }^{8)}$ In the cohesive zone, the ore particles undergo deformation due to softening and shrinkage. In this research, softening and shrinkage of ore particles in the cohesive zone were expressed by so-called overlapping as shown in Fig. 1, by using a smaller Young's modulus in the DEM. As the interparticle distance decreases, a condition approaching shrinkage of the layer occurs, and the void fraction decreases. The change in gas permeability, in other words, pressure drop, can be expressed by this change. Changes in the void fraction from the lumpy zone to the cohesive zone are expressed by the setting of Young's modulus, as discussed in the following sections. Below the cohesive zone, hold-up of the liquid phase occurs due to melting of the ore, and the void fraction also changes due to the effect of this phenomenon. In this model, the fraction value of the liquid phase in and below the cohesive zone was set at $0.20{ }^{6}$ )

\subsection{DEM Element Model Simulating Softening under Load}

DEM is used in motion analysis of non-steady solid flows, etc. It is possible to track the behavior of independent particles by solving a motion equation for all solid particles. The following describes the procedure for inter-contact force in DEM. ${ }^{6)}$ In DEM particles, the translational motion and rotational motion of the particles changes due to the stress and moment from the contact points between individual particles and between particles and a wall surface. Contact force can be calculated by the Voigt model, which approximates these behaviors by a spring, dash-pot, and friction slider, as shown in Fig. 1. The motion equation for particles which considers the contract force acting between particles can be expressed as follows for translational displacement $\boldsymbol{u}_{\boldsymbol{i}}$.

$$
m_{i} \frac{d^{2} \boldsymbol{u}_{i}}{d t^{2}}+\eta \frac{d \boldsymbol{u}_{i}}{d t}+K \boldsymbol{u}_{i}+\boldsymbol{f}_{g}+m_{i} \boldsymbol{g}=0
$$

Equation (2) is a similar equation expressing rotational displacement $\varphi_{i}$.

$$
I_{i} \frac{d^{2} \varphi_{i}}{d t^{2}}+\eta R_{i}^{2} \frac{d \varphi_{i}}{d t}+K R_{i}^{2} \varphi_{i}=0
$$

where, $\boldsymbol{f}_{\boldsymbol{g}}, \eta, m, R, I$, and $\boldsymbol{g}$ are a term representing external force, the coefficient of viscosity of the dash-pot and the mass, radius and moment of inertia, and gravitational acceleration, respectively. $K$ is a spring constant. The contact force $\boldsymbol{F}$ acting on a particle $j$ to $i$ is expressed as:

$$
\begin{gathered}
\boldsymbol{F}_{n, t}=\sum_{j}\left(\boldsymbol{e}_{n, t}+\boldsymbol{d}_{n, t}\right) \\
\boldsymbol{F}_{s, t}=\sum_{j}\left(\boldsymbol{e}_{s, t}+\boldsymbol{d}_{s, t}\right)
\end{gathered}
$$

Where $\boldsymbol{e}$ and $\boldsymbol{d}$ are elastic force expressed by the spring and the damping force expressed by the dash pot, and $n$ and $s$ 
denote normal and shear directions, respectively. The movement of the particles is calculated by the finite difference method by the time increment for the contact forces. The contact force is obtained from the relative displacement increment $\Delta u$ for a discrete time $\Delta t$.

$$
\begin{gathered}
\boldsymbol{e}_{n, t}=\boldsymbol{e}_{n, t-\Delta t}+K_{n} \Delta u_{n}, \boldsymbol{d}_{n, t}=\eta_{n} \frac{\Delta u_{n}}{\Delta t} \ldots \ldots \ldots \ldots . . . \\
K_{n}=2 D_{b}\left(\frac{1-v_{i}^{2}}{E_{i}}+\frac{1-v_{j}^{2}}{E_{j}}\right)^{-1}, \eta_{n}=2 \sqrt{m K_{n}} \ldots \ldots \\
\boldsymbol{e}_{s, t}=\boldsymbol{e}_{s, t-\Delta t}+K_{s} \Delta u_{s}, \boldsymbol{d}_{s, t}=\eta_{s} \frac{\Delta u_{s}}{\Delta t} \ldots \ldots \ldots \ldots \\
K_{s}=8 D_{b}\left(\frac{2\left(2-v_{i}\right)\left(1+v_{i}\right)}{E_{i}}+\frac{2\left(2-v_{j}\right)\left(1+v_{j}\right)}{E_{j}}\right)^{-1}, \\
\eta_{s}=2 \sqrt{m K_{s}}
\end{gathered}
$$

Where $E$ and $v$ denote the Young's modulus and Poisson's ratio of a particle, and $D_{b}$ is the radius of the contact circle.

Although the particles treated by DEM are spherical, blast furnace materials have an irregular shape. Therefore, changes in internal friction suited to coke, sinter, etc. were expressed by setting a coefficient of rolling friction on an inclined plane as a parameter expressing particle shape.9)

\subsection{Calculation of Changes in Packed Bed Structure}

In the softening test under load, the softening and shrinkage behavior of ore particles and resulting changes in pressure drop were measured by filling a cylindrical vessel with ore particles and heating the particles while applying a load to simulate the conditions in a blast furnace. In this research, the object of DEM calculations was a packed bed corresponding to the softening test under load apparatus shown in Fig. 2. As in the softening test under load, the simulation of changes in the structure of the packed bed was performed under a constant load of $0.1 \mathrm{MPa}$. The value of the load was determined according to the softening test under load, ${ }^{10)}$ where the standard conditions for the softening test was

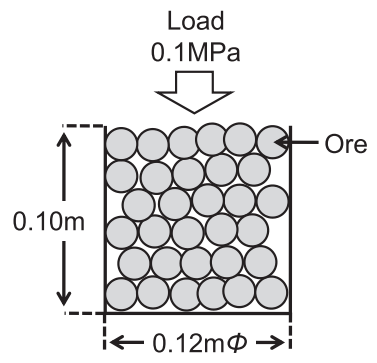

Fig. 2. Calculation field used in DEM simulation for softening behavior of ore particles. adopted. In the model, the packed bed is applied load by particle assemblage. The softening load model in Fig. 2 was prepared based on the DEM model described in the previous section, and changes in the layer structure of the packed bed were calculated. These calculations were performed by randomly filling particles with a diameter of $0.01 \mathrm{~m}$, assuming sinter, in a cylindrical vessel $0.12 \mathrm{~m}$ in diameter and $0.10 \mathrm{~m}$ in height, and giving a load of $0.1 \mathrm{MPa}$, as in the actual softening test under load. The amount of overlapping between particles in the packed layer changes due to the change in interparticle contact force when Young's modulus is intentionally changed, and the void fraction can be evaluated from the overlap of volume due to changes in the interparticle distance at this time. Conversion from the calculated particle arrangement information to void fraction was performed using the control volume method. $\left.{ }^{6}\right)$

The value of the Young's modulus of the ore particles was set at $0.50,0.10,0.05$, and $0.01 \mathrm{GPa}$, with $1.00 \mathrm{GPa}$ as a base. For the values of the other physical properties of the particles, the values for the particles when applied to the blast furnace were also applied here. ${ }^{9)}$ Table 1 shows the calculation conditions.

\subsection{Relationship between Young's Modulus and Changes in Void Fraction}

Figure 3 shows the structural changes in the packed bed when Young's modulus was set at $0.01 \mathrm{GPa}$. It is observed that the packed layer undergoes deformation and falls into a steady state. The calculation time shown here is the accelerated time in DEM. Figure 4 shows the results of a calculation of the structural changes in the packed layer when Young's modulus was changed to various values. In all cases, this is a layer structure after achieving a steady state. The void fraction $\varepsilon=\sum \mathrm{V}_{\text {particle }} / \mathrm{V}_{\text {unit }}$ in the packed layer for the respective values of Young's modulus was obtained from these calculation results. Here, $\mathrm{V}_{\text {particle }}=$ const . The results are shown in Fig. 5. As Young's modulus decreases, the void fraction also decreases. At values of Young's modulus of $0.02 \mathrm{GPa}$ and lower, the void fraction is approximately 0.17 .

In the softening test under load, pressure drop increased

Table 1. Calculation conditions used in DEM for softening behavior of ore particles.

\begin{tabular}{lccc}
\hline Diameter of particle & $d_{p}$ & 0.010 & {$[\mathrm{~m}]$} \\
Contact friction coefficient & $\mu_{i}$ & 0.30 & {$[-]$} \\
Rolling friction coefficient & $\alpha$ & 0.10 & {$[-]$} \\
Young's modulus & $E_{i}$ & $0.01-1.00$ & {$[\mathrm{GPa}]$} \\
Poisson's ratio & $v_{i}$ & 0.24 & {$[-]$} \\
Apparent density & $\rho_{i}$ & $3.95 \times 10^{3}$ & {$\left[\mathrm{~kg} / \mathrm{m}^{3}\right]$} \\
Time step & $\Delta t$ & $1.0 \times 10^{-6}$ & {$[\mathrm{~s}]$} \\
\hline
\end{tabular}

Young's modulus of ore particles:0.01GPa

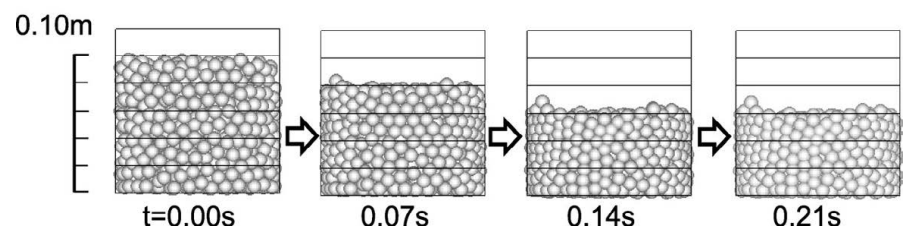

Fig. 3. Structural change in ore packed bed under load calculated by DEM. 


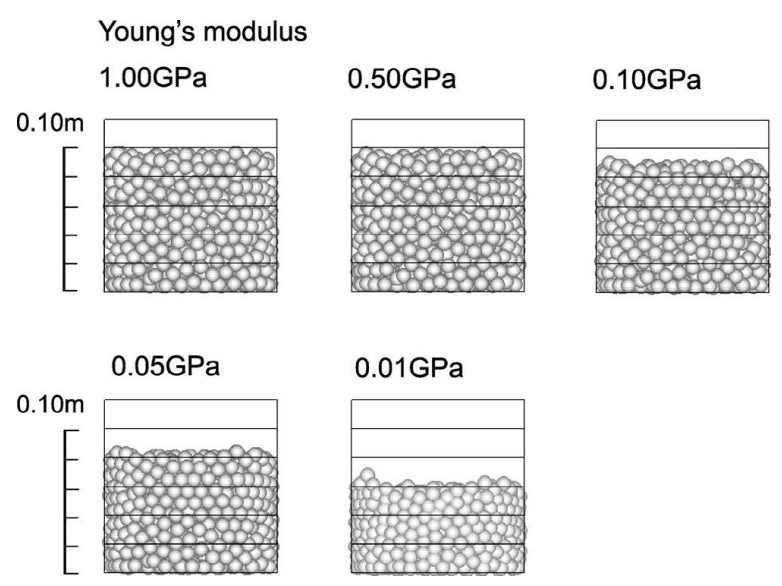

Fig. 4. Influence of Young's modulus on structural change in ore packed bed calculated by DEM.

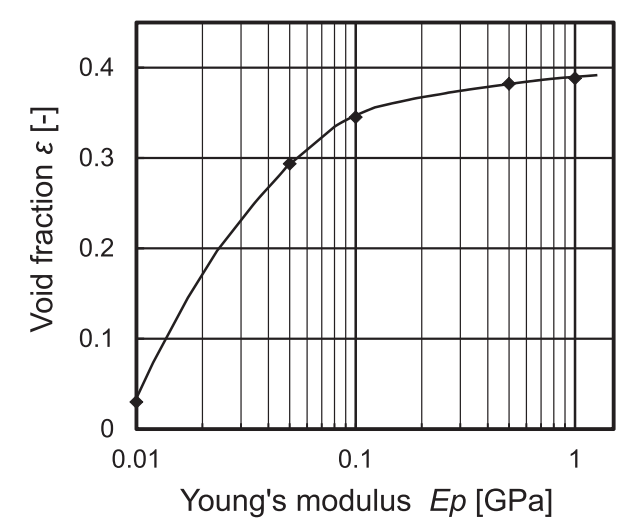

Fig. 5. Relationship between void fraction and Young's modulus calculated by DEM.

remarkably due to softening and shrinkage of the ore at temperatures of approximately $1200^{\circ} \mathrm{C}$ and higher. That behavior changes greatly, depending on the ore properties. Maximum pressure drop shows an increase of approximately 15 times, ${ }^{10)}$ or a greater increase than this, ${ }^{11)}$ at temperatures of $1200^{\circ} \mathrm{C}$ and lower. This is not a numerically consistent trend. However, in the present research, the authors referred to the former result. ${ }^{10)}$ Figure 6 shows the relationship between relative pressure drop and the void fraction obtained using Ergun's equation. In this figure, the initial value of the void fraction was 0.38 , and the increase in pressure drop due to the decrease in the void fraction was obtained, based on the pressure drop at that time. From this figure, it can be understood that the value of pressure drop increases by approximately 15 times around a void fraction of 0.17 . Assuming the above-mentioned maximum increase in pressure drop of approximately 15 times, which was used as reference in this research, from Figs. 5 and 6, the decrease to a Young's modulus of $0.02 \mathrm{GPa}$ corresponds to an increase in pressure drop by way of a decrease in the void fraction. Accordingly, from these results, it is considered that changes in gas permeability in the cohesive zone accompanying softening and shrinkage of the sinter can be expressed by setting Young's modulus at $0.02 \mathrm{GPa}$ in the DEM. Shimoda et al. attempted a quantitative conversion of the $\mathrm{K}$ value obtained from a softening experiment under load to permeability. ${ }^{12)}$ However, because the $\mathrm{K}$ value is linked directly to the particular conditions of the softening test under load, it is difficult to use the $\mathrm{K}$ value as universal

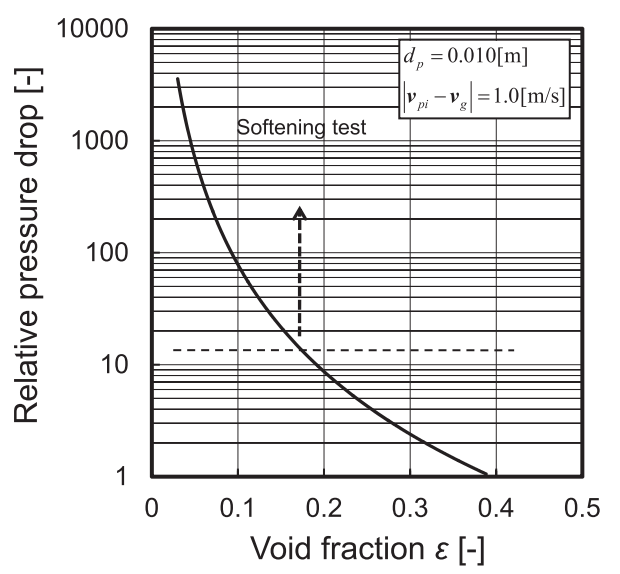

Fig. 6. Relationship between change in pressure drop and void fraction calculated by Ergun's equation.

information on changes in permeability.

\section{Blast Furnace DEM-CFD Model Considering Cohe- sive Zone}

\subsection{Blast Furnace DEM-CFD Model}

The blast furnace model was based on a DEM-CFD model developed by Natsui et al. ${ }^{6)}$ As the CFD calculation, the term $f_{g}$ expressing interaction force between particles and a fluid was added to the Navier-Stokes equation, and Ergun's equation or the Wen-Yu equation was used in the external force term, corresponding to the void fraction. The following shows the basic CFD equations.

$$
\begin{aligned}
& \frac{\partial}{\partial t}\left(\varepsilon \rho_{g}\right)+\nabla \cdot\left(\varepsilon \rho_{g} v\right)=0 \\
& \frac{\partial}{\partial t}\left(\varepsilon \rho_{g} v\right)+(\boldsymbol{v} \cdot \nabla) \varepsilon \rho_{g} \boldsymbol{v}=-\varepsilon \nabla \boldsymbol{p}+\varepsilon \mu_{g} \nabla^{2} \boldsymbol{v}+\boldsymbol{f}_{g} \ldots \\
& \boldsymbol{f}_{g}=N_{i} C_{g-p} \varepsilon\left(\boldsymbol{v}_{p i}-\boldsymbol{v}_{g}\right) \\
& C_{g-p}=\left\{\begin{array}{c}
\frac{\mu_{g}(1-\varepsilon)}{\rho_{g} \varepsilon^{2} d_{p}^{2}}[150(1-\varepsilon)+1.75 \mathrm{Re}] \quad(\varepsilon \leq 0.8) \ldots \\
\frac{3}{4} C_{D} \frac{\mu_{g}(1-\varepsilon)}{\rho_{g} \varepsilon^{3.7} d_{p}^{2}} \cdot \operatorname{Re} \quad(\varepsilon>0.8)
\end{array}\right. \\
& C_{D}=\left\{\begin{array}{c}
24\left(1+0.15 \operatorname{Re}^{0.687}\right) / \operatorname{Re} \quad(\operatorname{Re} \leq 1000) \\
0.43 \quad(\operatorname{Re}>1000)
\end{array} \ldots\right. \\
& \operatorname{Re}=\frac{\left|\boldsymbol{v}_{p i}-\boldsymbol{v}_{g}\right| \rho_{g} \varepsilon d_{p}}{\mu_{g}}
\end{aligned}
$$

In Eqs. (3) and (4), $\varepsilon, \boldsymbol{v}, \boldsymbol{p}, \rho_{g}, \mu_{g}$, and $\boldsymbol{f}_{\mathrm{g}}$ express the void fraction, velocity vector, pressure, density, viscosity, and an external force term, respectively. In Eq. (5), $N_{i}, \boldsymbol{v}_{p i}$, and $\boldsymbol{v}_{g}$ show the number of particles in a cluster, particle velocity, and gas velocity, respectively. Chemical reactions and heat transfer are not included in this model. The above calculation procedures were carried out in the isotherm state.

\subsection{Calculation Method}

As the object of calculation, an actual size blast furnace 
with an inner volume of $5000 \mathrm{~m}^{3}$ class was used, as shown in Fig. 7. As shown in the same figure, this is a 3-dimensional model of one-half of the furnace. The cross section has a periodic boundary condition. Number of tuyere is 40 . The number of particles in DEM was 0.6 million as standard. The bell top system was used for raw material charging. The region of the cohesive zone is greatly influenced by burden and operating conditions. However, in this calculation, the standard inverted-V cohesive zone shape shown in Fig. 7 was assumed, and its range was set. The thickness of the cohesive zone was set at $4.0 \mathrm{~m}$, and the ore layer was eliminated below the cohesive zone.

Figure 8 shows the concept when this model is applied to the blast furnace. At the charging, the initial value of Young's modulus is assumed to be $1.00 \mathrm{GPa}$ for both ore and coke. In the cohesive zone, the Young's modulus of the ore is assumed to be $0.02 \mathrm{GPa}$, as obtained from the results of the softening test under load. Ore particles are erased below the cohesive zone based on supposition that they become liquid phase, and correction of void fraction was applied below that area. The Young's modulus of the coke is assumed to be constant at $1.00 \mathrm{GPa}$ in all parts of the furnace.

In coupling DEM and CFD, the particle motion of clustered ore and coke are calculated by DEM equations described in section 2.2 , and the void fraction surrounding the particles is calculated from the particle positions. This void fraction information is then input to the CFD. The method of these DEM-CFD models is the same as that in the paper by Natsui et al. ${ }^{6}$ The DEM-CFD calculation conditions are shown in Table 2. Since the number of particles which can be handled in DEM is limited by computer capac-

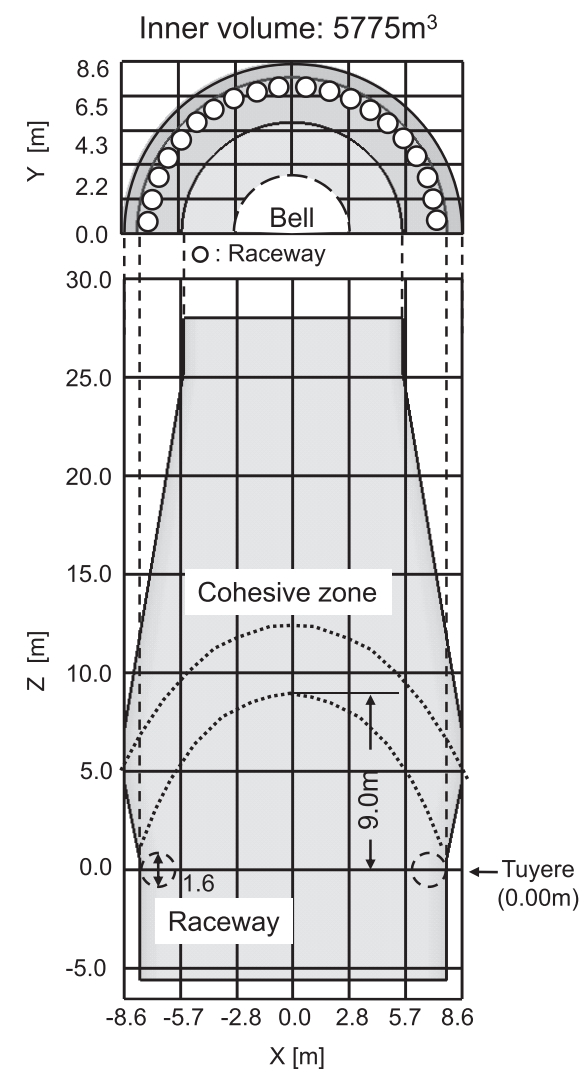

Fig. 7. Schematic diagram of three-dimensional calculation region of blast furnace with inner volume of over $5000 \mathrm{~m}^{3}$. ity, an enlarged particle diameter is used in the DEM model, assuming that multiple particles exist as clusters. In the CFD calculation, which is linked to the gas flow calculation, particle diameters close to those of actual particles were used, the values being $0.050 \mathrm{~m}$ for coke and $0.020 \mathrm{~m}$ for ore.

\section{Calculation Results}

\subsection{Void Fraction Distribution and Gas Velocity Vectors}

DEM-CFD simulation is also calculated continuously. It is unsteady simulation, and brief moment of state is observed. All calculation results are the states of $1.5 \mathrm{~s}$ in DEM after finishing contraction. Figure 9 shows the distribution of the void fraction in the vicinity of the cohesive zone without and with a cohesive zone, based on the abovementioned calculations. In this calculation, the region of the cohesive zone was set in advance, and softening and shrinkage of the ore were expressed by intentionally reducing the Young's modulus of the ore in that part. As the void fraction decreases in the region where the ore layer exists in the assumed cohesive zone, and the number of particles becomes dense, the existence of a so-called cohesive layer and coke slits can be confirmed from the calculation results shown in Fig. 9. In Fig. 9, void fraction of cohesive zone is under 0.1 . This value is corresponding to the result of blast

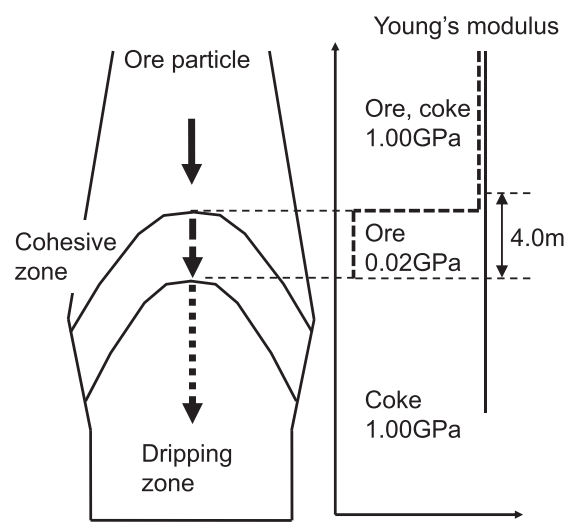

Fig. 8. Change in Young's modulus during burden descending in blast furnace.

Table 2. Calculation conditions used in DEM-CFD.

\begin{tabular}{lcc}
\hline Maximum Particle number in DEM & 600000 & {$[-]$} \\
\hline Diameter of particle (coke, ore) DEM & $0.300,0.150$ & {$[\mathrm{~m}]$} \\
CFD & $0.050,0.020$ & \\
\hline Poisson's of particle (coke, ore) & $0.21,0.24$ & {$[-]$} \\
Apparent density (coke, ore) & $1.1,4.0$ & {$\left[\mathrm{~kg} / \mathrm{m}^{3}\right]$} \\
\hline Young's modulus (coke) & 1.00 & \\
Young's modulus (ore) & 1.00 & {$[\mathrm{GPa}]$} \\
$\quad$ above cohesive zone & 0.02 & {$[-]$} \\
\hline in cohesive zone & $790372(121 \times 46 \times 142)$ & {$\left[\mathrm{m}{ }^{2}\right]$} \\
\hline Number of grids & 0.0560 & {$[\mathrm{~m} / \mathrm{s}]$} \\
\hline Inlet area of tuyere & 87.2 & {$[\mathrm{~s}]$} \\
\hline Inlet velocity & $1.0 \times 10^{-4}, 7.2$ & \\
\hline Time step (DEM, CFD) &
\end{tabular}


furnace dissection. ${ }^{13)}$ Furthermore, it can be understood that bending curvature occurs in the layer directly above the cohesive zone, reflecting the shrinkage of the ore layer in the cohesive zone.

Figure 10 shows the results of a calculation of the gas velocity vectors in the same region as in Fig. 9. In the case without a cohesive zone, this comprises gas velocity vectors in substantially the upward direction, whereas, in the model with the cohesive zone, a condition in which the gas flow changes direction from the center to the wall by passing through coke slits can be observed. Irita et al. calculated the gas flow by the finite element method based on a cohesive zone shape obtained using a pseudo-hot model. ${ }^{14)}$ Although the calculation method is different, the tendency of the gas flow in that study agrees with this calculation based on a layered structure. Since it is impossible to measure the changes in the structure of the cohesive zone in an actual blast furnace, the results of blast furnace dissection in the past are used as a source of this information. ${ }^{15,16)}$ As the results of this model calculation are also close to blast furnace dissection results, it appears that structural changes in

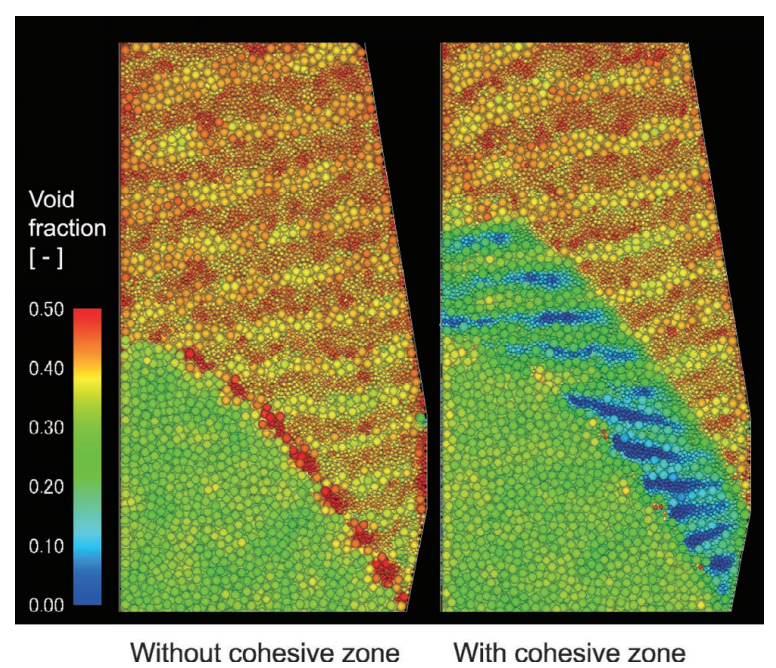

Fig. 9. Comparison of void fraction in vicinity of cohesive zone without and with cohesive zone.

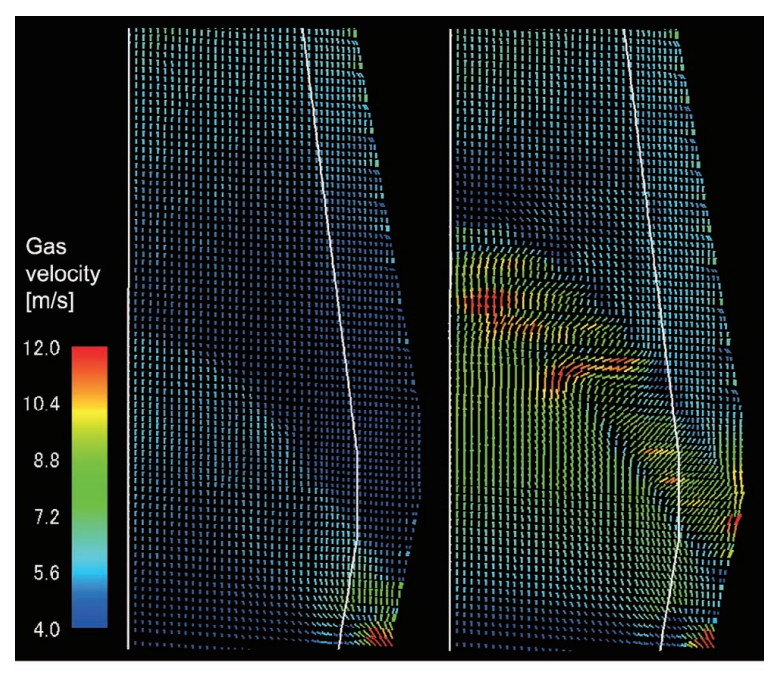

Without cohesive zone

With cohesive zone

Fig. 10. Comparison of gas velocity vectors change in vicinity of cohesive zone. the cohesive zone can be expressed by this model.

\section{Changes in Gas Flow under Reduced Coke Rate}

\subsection{Calculation Conditions for Low Coke Rate Opera- tion}

As mentioned in the introduction, reduction of the carbon input for blast furnace is now demanded as a means of reducing $\mathrm{CO}_{2}$ emissions in steel works. To achieve a large reduction in the carbon requirement of the blast furnace, methods of introducing reducing gas from outside the system, such as recycling of furnace top gas, have been proposed. ${ }^{17,18)}$ The coke rate can be significantly reduced to around $200 \mathrm{~kg} / \mathrm{t}$ by active top gas recirculation. ${ }^{18)}$ However, operation under this condition greatly reduces the amount of coke which is used to maintain permeability, and deterioration of permeability becomes a concern, particularly in the vicinity of the cohesive zone. Although a number of process-related studies have been carried out on top gas recycling process, there are no examples of analysis of the gas flow in the blast furnace in such low coke rate operation. Therefore, in the present research, the gas flow was calculated under a greatly reduced coke rate utilizing the features of this model, assuming future low coke rate operation in future.

A coke rate of $350 \mathrm{~kg} / \mathrm{t}$ was assumed as the standard condition (case a), and $240 \mathrm{~kg} / \mathrm{t}$ was assumed as the low coke rate condition (case b). Due to restrictions on the number of particles in DEM calculations, when setting the layer thickness, the thickness of the coke layer was assumed to be constant, and only the thickness of the ore layer was changed. The amount of gas per unit of time was assumed to be constant in both.

\subsection{Results of Calculation of Void Fraction and Gas Flow in Low Coke Rate Operation}

Figure 11 shows the burden layer structure calculated by DEM, and Fig. 12 shows distribution of the void fraction in the blast furnace calculated by DEM. In the shaft, the dis- a) Coke rate $350 \mathrm{~kg} / \mathrm{t}$

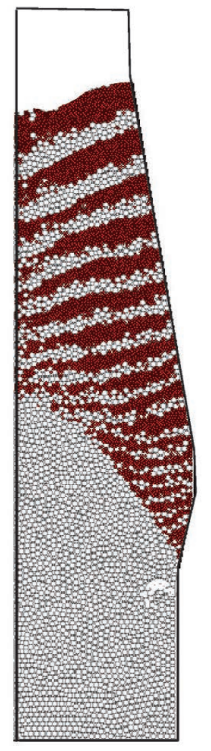

b) Coke rate $240 \mathrm{~kg} / \mathrm{t}$

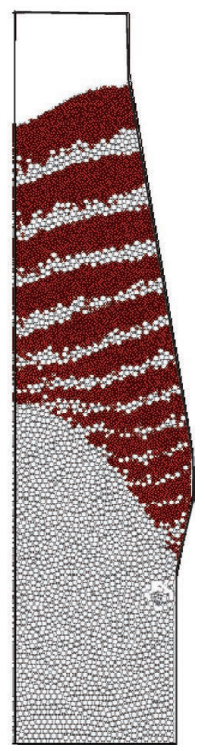

Fig. 11. Burden layer in blast furnace for each coke rate condition calculated by DEM (red particle:ore, gray particle:coke). 
tribution of the void fraction corresponds to the layered structure of the ore layer and coke layer. However, in the cohesive zone, a low void fraction region can be observed, as shown in blue in Fig. 12. In case a) for $350 \mathrm{~kg} / \mathrm{t}$, layers corresponding to coke slits can be seen, but in case b), the low void fraction region expands and that region becomes dense. The shape of the coke slits is somewhat unclear due to the sensitivity of the control volume in CFD. In the future, improved spatial resolution can be expected, assuming improved computer capabilities.

Figure 13 shows the gas velocity vectors in the total furnace. Even in the standard case a), a gas flow passing through the coke slits toward the furnace wall can be observed in the vicinity of the cohesive zone. However, under the low coke rate operation in case b), this gas flow toward the wall becomes stronger. Figure 14 shows an enlarged view of the gas velocity vectors in the vicinity of the cohesive zone. In both a) and b), movement of the gas flow velocity corresponding to the coke slits can be seen, however in b), in which the thickness of the ore layer increases, an intensified gas flow, as shown by the red vectors, appears over a wide range. In particular, the fact that an intensified gas flow impacting on the wall can be observed at the root of the cohesive zone is a distinctive fea-

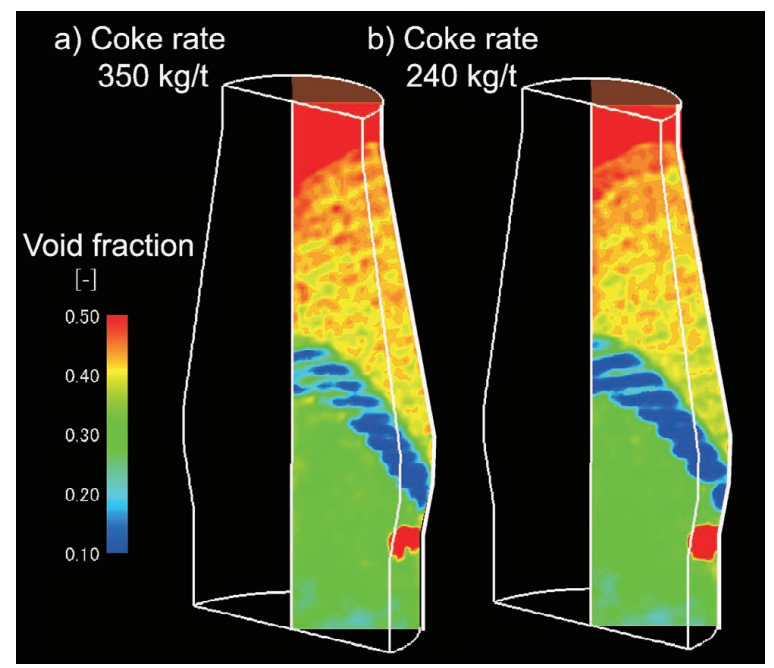

Fig. 12. Influence of coke rate on void fraction in blast furnace.

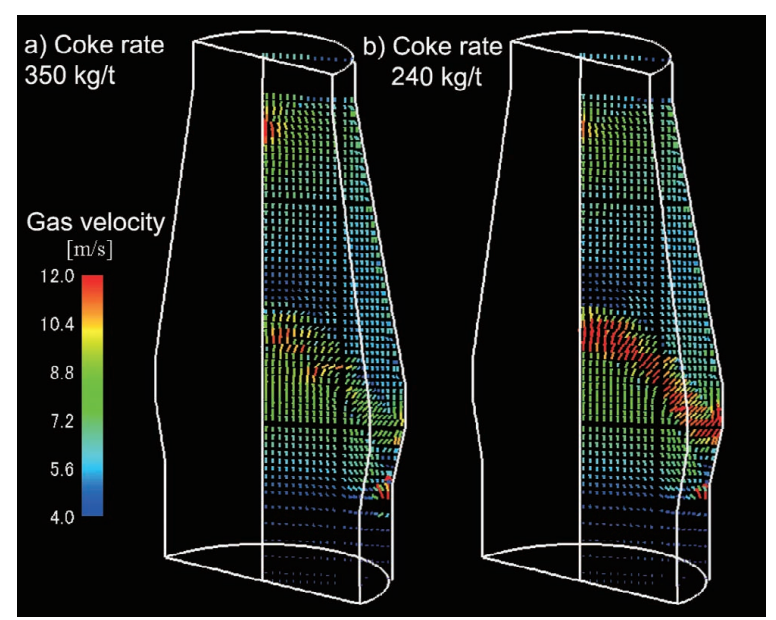

Fig. 13. Influence of coke rate on gas velocity vectors in blast furnace. ture of low coke rate operation. In the cohesive zone in a), a slight gas flow can also be seen passing through the ore layer, in spite of its low void fraction. However, in case b), the difference between that flow and the gas flow passing through the coke slits becomes remarkable.

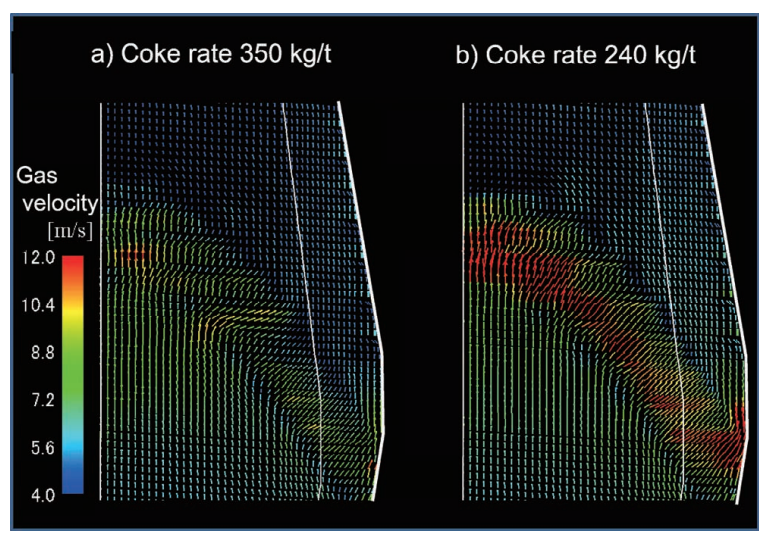

Fig. 14. Enlarged view of gas velocity vectors in vicinity of cohesive zone showing influence of coke rate.

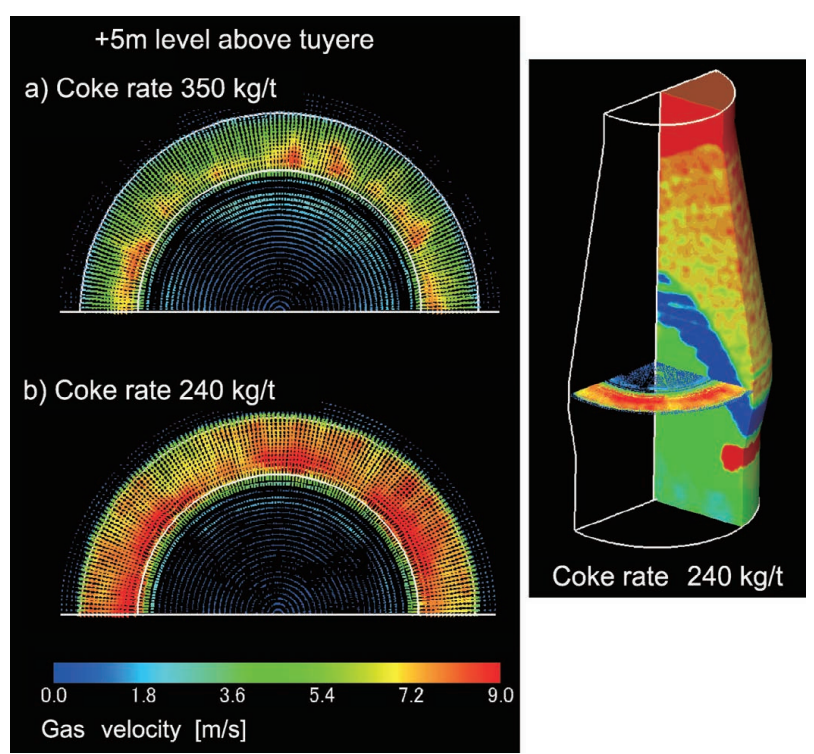

Fig. 15. Horizontal gas velocity vectors in cohesive zone.

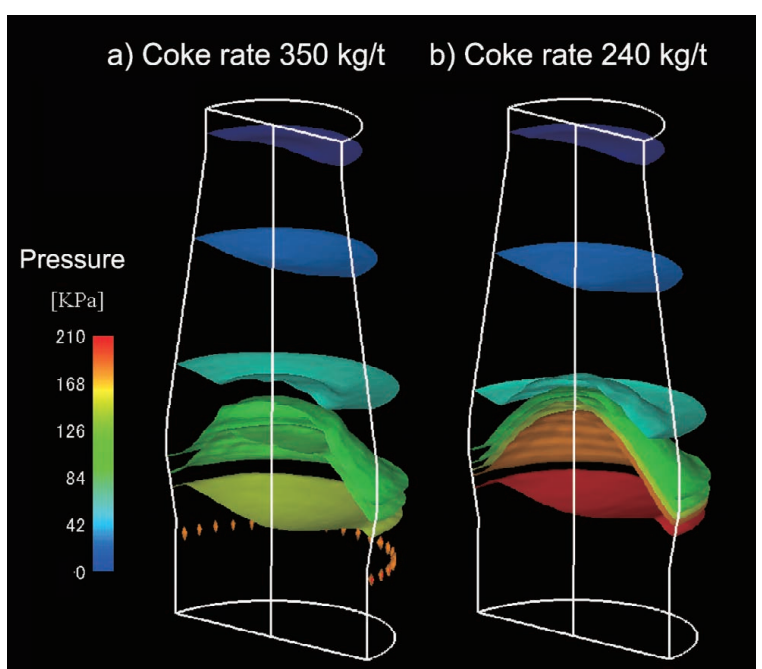

Fig. 16. Comparison of isobar planes for different coke rate conditions. 
The horizontal gas velocity vectors in the furnace cross section at a point $5 \mathrm{~m}$ above the tuyere line is shown in Fig. 15. Inside the ring-shaped cohesive zone, in other words, in the region corresponding to the deadman, the upward gas flow occupies the greater part of the gas flow, and as a result, virtually no horizontal gas flow can be observed. On the other hand, in the ring-shaped cohesive zone, a gas flow toward the wall can be seen. In case b), the horizontal gas vectors becomes significantly strong due to the increase in the ore layer thickness and decrease in the number of coke slits in the cohesive zone. As mentioned above, an intensified gas flow to the wall can be observed.

Looking at the gas flow distribution in the circumferential direction, in both a) and b), the gas velocity in the circumferential direction is not uniform, and the gas flow is concentrated in specific directions. In DEM, motion is tracked by individual particles from the formation of the burden distribution at the furnace top until descent. In other words, since descent is determined by the stochastic particle motion of individual particles, a local distribution of the void fraction will always exist in the radial and circumferential directions. Because the gas flow responds sensitively to the distribution of the void fraction, it can be conjectured that non-uniformity of the void fraction and layer thickness distribution appears in the circumferential direction due to the effect of the void fraction and layer thickness distributions, etc. generated in the circumferential direction. Likewise, there is also a possibility that similar phenomena essentially occur in actual blast furnaces due to the formation of a distribution during charging and the descending motion, which comprises individual particles. As circumferential nonuniformity is an extremely interesting phenomenon which is related to stable operation of the blast furnace, continuing analysis of this issue is planned.

Figure 16 shows the distribution of isobar planes. In the results of calculations in the previous report, which did not consider the cohesive zone, the distribution of isobar planes in the furnace was substantially flat. ${ }^{6)}$ In contrast, the calculations using this model reflect changes in pressure drop in the cohesive zone, and these isobar planes show large distortions in the furnace bottom. In particular, under the low coke rate condition in $b$ ), the results reflect that fact that the isobar planes are located close together in the area around the cohesive zone, and pressure drop increases in this area. Thus, it can be predicted that increased pressure drop in the vicinity of the cohesive zone will become an operational problem due to an orientation toward low coke rate operation.

Thus, in summary, it appears to be possible to analyze changes in the gas flow in the blast furnace using this model, which can reproduce the layered structure and gas flow in the cohesive zone in a comprehensive manner.

\section{Conclusion}

In order to express the softening and shrinkage of ore in the cohesive zone region, which are key elements in the phenomena in the blast furnace, a model in which the Young's modulus of sinter particles is changed in the cohesive zone was constructed in a DEM-CFD blast furnace model. The results obtained in this research is summarized below.

(1) A DEM model was built for the softening test under load, and an element model establishing correspondence between the changes in blast furnace permeability accompanying softening and shrinkage of the ore layer and the Young's modulus of ore particles was constructed. Softening and shrinkage are expressed by overlapping of the particles in the DEM element model, and the appropriate Young's modulus for reproducing the cohesive zone was determined from a comparison of permeability with the results of a softening test under load.

(2) By applying this model, which expresses softening and shrinkage, to the region of the cohesive zone in the blast furnace model, it is possible reproduce the softening and melting behavior of ore in the cohesive zone and the changes in its effect on gas flow.

(3) Due to the softening behavior of the ore particle, the void fraction of ore layer in the cohesive zone decreases greatly and coke slits appear. The fact that the gas flow is greatly influenced by the existence of these gas slits could be confirmed using the model.

(4) Taking advantage of the distinctive characteristics of this model, the gas flow at the low coke rate operation was analyzed, confirming that the gas flow in the cohesive zone changes remarkably under low coke rate operation, and in particular, the gas flow at the root of the cohesive zone strengthens.

As described above, a model was constructed, in which the dynamic influence of ore softening and shrinkage in the blast furnace on gas flow is reflected by expressing the softening and shrinkage behavior of ore in the cohesive zone, and the effectiveness of this model was demonstrated. In the future, it appears that this model can be used as an effective method for constructing a comprehensive model of the blast furnace by linking the model with temperature distribution information.

\section{REFERENCES}

1) J. A. Castro, H. Nogami and J. Yagi: ISIJ Int., 42 (2002), 44.

2) H. Nogami and J. Yagi: ISIJ Int., 44 (2004), 1826.

3) S. Ueda, S. Natsui, H. Nogami, J. Yagi and T. Ariyama: ISIJ Int., 50 (2010), 914.

4) T. Nouchi, T. Sato, M. Sato and K. Takeda: Tetsu-to-Hagané, 92 (2006), 955.

5) H. Mio, K. Yamamoto, A. Shimosaka, Y. Shirakawa and J. Hidaka: ISIJ Int., 47 (2007), 1745.

6) S. Natsui, H. Nogami, S. Ueda, J. Kano, R. Inoue and T. Ariyama: ISIJ Int., 51 (2011), 41.

7) P. R. Austin, H. Nogami and J. Yagi: ISIJ Int., 37 (1997), 458.

8) S. Ueda, S. Natsui, Z. Fan, H. Nogami, R. Soda, J. Kano, R. Inoue and T. Ariyama: ISIJ Int., 50 (2010), 981.

9) S. Natsui, S. Ueda, Z. Fan, J. Kano, R. Inoue and T. Ariyama: Tetsuto-Hagané, 96 (2010), 1.

10) H. Hotta and Y. Yamaoka: Tetsu-to-Hagané, 71 (1985), 807.

11) T. Irita, T. Isoyama, Y. Hara, Y. Okuno, O. Mikuni and K. Tashito: Tetsu-to-Hagané, 66 (1980), S706.

12) T. Shimoda, K. Kurita and Y. Iwanaga: Tetsu-to-Hagané, 70 (1984), 665.

13) S. Hashizume and H. Takahashi: Kawasaki Steel Giho, 3 (1979), 388.

14) T. Irita, T. Isoyama, Y. Hara, Y. Okuno, Y. Kanayama and K. Tashiro: Tetsu-to-Hagané, 68 (1982), 2295.

15) K. Kanbara, T. Hagiwara, A. Shigemi, S. Kondo, Y. Kanayama, K. Wakanayashi and N. Hiramoto: Tetsu-to-Hagané, 62 (1976), 535.

16) Y. Shimomura, K. Nishioka, S. Arino, T. Katayama, Y. Hida and T. Isoyama: Tetsu-to-Hagané, 62 (1976), 547.

17) P. Schmöle, B. Korthas and H. B. Lüngen: METEC INSTEEL Con., Session 17, Steel Institute VDEh, Düsseldorf, (2011).

18) R. Murai, M. Sato and T. Ariyama: ISIJ Int., 44 (2004), 2168. 